\title{
Yaşlılıkta Görülen Destrüktif Osteoartrit: Olgu Sunumu
}

\author{
Destructive Osteoarthritis in Elderly: Case Report \\ Canan Çelik, Asiye Mukaddes Erol, Şeniz Akçay Yalbuzdağ, Banu Karabulut* \\ Bursa Şevket Yılmaz Eğitim ve Araştırma Hastanesi, Fiziksel Tıp ve Rehabilitasyon Kliniği, Bursa, Türkiye \\ *Bursa Şevket Yılmaz Eğitim ve Araştırma Hastanesi, Radyoloji Kliniği, Bursa, Türkiye
}

\section{Özet}

Destrüktif osteoartrit, çoğunlukla 75 yaşın üzerindeki kadınlarda görülmektedir. Bu raporda, sol omuz ve bilateral ayak bileğinde destrüktif osteoartriti olan yaşlı bir hastanın sunulması amaçlanmıştır. Yetmiş iki yaşında kadın hasta, bir yıldır giderek artan sol omuz ve ayak bileklerinde ağıı nedeniyle başvurmuştu. Özgeçmişinde, 23 yıl önce ayak bileklerine direkt maruz kaldığı bir travma mevcuttu. Fizik muayene, sol omuz ve ayak bilek eklem hareketlerinin kısıtlı ve ağrılı olduğunu göstermekteydi. Ayak bileği ve sol omuz eklemlerinin radyografilerinde saptanan santral erozyonlar, periartiküler skleroz, kistler, osteofit oluşumları, eklem mesafesinde daralma ve kortikal destrüksiyon, destrüktif osteoartrit ile uyumluydu. Bu olgu sunumu ile, yaşıı kadınlarda disabilite nedeni olabilen destrüktif osteoartrit vurgulanmıştır. (Türk Osteoporoz Dergisi 2013;19: 84-6)

Anahtar kelimeler: Destrüktif osteoartrit, omuz, ayak bileği

\section{Summary}

Destructive osteoarthritis is more frequently seen in women over the age of 75. In this report, the aim was to present an elderly patient with destructive osteoarthritis at the left shoulder and bilateral ankle. Seventy-two-year-old female patient had admitted with progressively increasing pain at the left shoulder and ankles since one year. In her history, there was a direct trauma exposure to ankles 23 years ago. Pyhsical examination revealed limited and painful motions of left shoulder and ankle joints. Central erosions, periarticular sclerosis, cysts, osteophyte formations, joint space narrowing and cortical destruction which were detected in ankle and left shoulder joints plain radiographs were compatible with destructive osteoartritis. By this case, destructive osteoarthritis which can be the cause of disability in elderly women is emphasized. (Turkish Journal of Osteoporosis 2013;19: 84-6)

Key words: Destructive osteoarthritis, shoulder, ankle

\section{Giriş}

Yaşlılıkta görülen destrüktif osteoartrit, osteoartriti olan yaşlı bireylerde, daha çok 75 yaşın üzerindeki kadınlarda gelişmektedir. Karakteristik olarak eklemin iki tarafındaki subkondral kemikte ağır destrüksiyon, yumuşak doku hasarı ve kıkırdak kaybı görülür. En sık omuzda gelişmesine rağmen kalça, diz eklemi ve diğer eklemlerde de görülmekte ve aynı kişide birden fazla eklem tutulabilmektedir $(1,2)$. Sol omuz ve bilateral ayak bileğinde destrüktif osteoartriti olan yaşıı bir hastayı sunmayı amaçladık.

\section{Olgu Sunumu}

Yetmiş iki yaşında kadın hasta, bir yıldır artan her iki ayak bileği ve sol omuzda ağrı şikayeti ile başvurmuştu. Bilateral ayak bileğindeki ağrı şiddeti, görsel analog skala ile 9, sol omuz ağrısı ise 5 olarak değerlendirildi. Öz geçmişinde 23 yı önce ayaklarından ipe dolanarak sürüklenme şeklinde bir travma tanımlıyordu. Hipertansiyon öyküsü mevcuttu. Yirmi beş yıl önce akciğer tüberkülozu geçirmişti. Kas iskelet sistemi muayenesinde, torakal kifoz, torakolomber paravertebral hassasiyet ve spazm mevcut olup, sol omuz fleksiyonu 90, abduksiyonu 80 , iç/dış rotasyonu 30/40 derecede ağrılı ve limitliydi. Bilateral ayak bileği dorsifleksiyonu 5 derecede limitli, plantar fleksiyonu sağda 15 , solda 5 derecede limitli ve ağrlıydı. Inversiyon/eversiyon sağda 15/8, solda 10/5 dereceydi. Pes planovalgus ve halluks valgus mevcuttu. Vücut kitle indeksi 32 olan hastanın laboratuar analizlerinde, ESR $24 \mathrm{~mm} / \mathrm{sa}, \mathrm{CRP} 3,3 \mathrm{mg} / \mathrm{L}, \mathrm{RF}$ 9,9 IU/mL, anti-CCP ve ANA (-), 25-hidroksi D vitamini $51,4 \mathrm{ng} / \mathrm{mL}$ $(6,23-49,9)$ idi. Hiperkolesterolemi mevcut olup, hemogram ve diğer biyokimyasal tetkikleri normaldi.

Bilateral ayak bileği radyografilerinde, tibiotalar eklem aralığında ileri derecede daralma, talar kubbede belirgin talus ve tibiada

Yazıșma Adresi/Address for Correspondence: Dr. Canan Çelik, Bursa Şevket Yılmaz Eğitim ve Araştırma Hastanesi, Fiziksel Tıp ve Rehabilitasyon Bölümü, Bursa, Türkiye

Tel.: +90 22429550 00/103 E-posta: ccelik@hotmail.com Geliș Tarihi/Received: 04.10.2013 Kabul Tarihi/Accepted: 14.11.2013

Türk Osteoporoz Dergisi, Galenos Yayınevi tarafindan basılmıştır. / Turkish Journal of Osteoporosis, published by Galenos Publishing. 
destrüksiyon santral erozyonlar, periartiküler skleroz, kist ve osteofit oluşumları izlenmekteydi (Şekil 1,2,3). Sol omuz grafisinde, eklem mesafesinde daralma, glenoid ve humerus başında kortikal destrüksiyon, lateral osteofit oluşumu ve humerus başının superolaterale yer değiştirdiği görülmekteydi (Şekil 4). Dejeneratif bulgular Kellgren-Lawrence sınıflamasına göre grade 4 olarak değerlendirildi (3). Torakal grafide T6 ve T11 vertebralarda kompresyon fraktürü mevcuttu. Kemik mineral dansitometrisinde femur boyun T skoru -2,7, lomber total T skoru -1,7 olarak saptandı. Üç fazlı total vücut kemik sintigrafisinde sol omuz ekleminde, T6-7, L1, L3 ve L4 vertebralarda, bilateral ayak bileği eklemlerinde yoğun aktivite tutulumu, dejeneratif değişiklikler lehine değerlendirildi. Barthel İndeksi 70 olup, günlük yaşam aktivitelerinde orta derecede bağımlıydı. Hastamız osteoporoz ve destrüktif osteoartrit tanılarıyla fizik tedavi ve rehabilitasyon programına alındı.

\section{Tartışma}

Glenohumeral osteoartrit, yük taşıyan eklemlerin osteoartritine göre daha nadir görülmektedir. Humerus başı osteonekrozunun doğal seyrinde oluşan osteoartrit dışında, primer (santral veya eksantrik) olarak gelişebilir, ya da non-eksantrik osteoartrit (genellikle rotator kılıfın dejeneratif lezyonuna sekonder) şeklinde ortaya çıkabilir $(4,5)$. Omuzun idiyopatik destrüktif artriti, özellikle yaşlı kadınlarda görülmekte olup, patojenezi tam olarak anlaşılamamıştır. Primer olarak omuzda görülmekle birlikte, kalça, diz ve diğer eklemlerde de görülebilmektedir. Bazen aynı kişide birden fazla eklem tutulabilir $(1,2)$. Klinik olarak sıklıkla rotator kllıf rüptürü ile birlikte olup, effüzyon, aktiviteyle artan omuz ağrısı ve hareket kısıtlılı̆ı ile karakterizedir. Radyolojik olarak, yumuşak doku şişliği ve belirgin destrüksiyonun eşlik ettiği subkondral skleroz saptanabilir $(2,6)$.

Erişkin popülasyonun yaklaşık \%1'inde ayak bileği osteoartriti görülmektedir (7). Ayak bileğinde semptomatik osteoartrit sıklığı, diz ve kalça ekleminden 9 kez daha azdır (8). Diz ve kalça ekleminin aksine, ayak bileğinde daha çok postravmatik osteoartrit görülmektedir $(7,9)$. Ayak bileği ekleminin primer osteoartriti, travma veya herhangibir sekonder veya infeksiyöz osteoartrit hikayesi olmayanlarda nadir görülmektedir $(10,11)$. Çoğunlukla malleol kırıkları olmak üzere, ligaman lezyonları ve tibial plafond fraktürlerine sekonder olarak gelişmektedir. Postravmatik veya sekonder osteoartriti olan hastalar, çoğunlukla primer osteoartriti olan hastalardan daha gençtir (10). Victor ve ark. (10), tüm osteoartritler arasında, ayak bileği ekleminin primer osteoartritini, \%9 oranında bulmuşlardır. Ayak bileği kartilajı (1,0-1,62 mm), diz $(1,69-2,55 \mathrm{~mm})$ ve kalça kartilajından $(1,35-2,0 \mathrm{~mm})$ daha ince olmasına rağmen, kompresif sertliğinin ve proteoglikan dansitesinin daha yüksek, matriks degredasyonunun daha düşük olduğu ve katabolik stimülasyonlara cevabının (interlökin 1, fibronektin fragmanları) daha az olduğu gözlenmektedir. Relatif olarak kartilaj rezistansının daha yüksek olması, primer osteoartrite yol açan dejeneratif değişikliklerden ayak bileği eklemini koruyabilmektedir (10). Ea ve ark. (12), farelerde yaptıkları deneysel çalışmada, diz ekleminde temel kalsiyum kristallerinin sinovial enflamasyon, kartilaj degredasyonu ve kondrosit apopitozuna yol açtığını, gözlenen
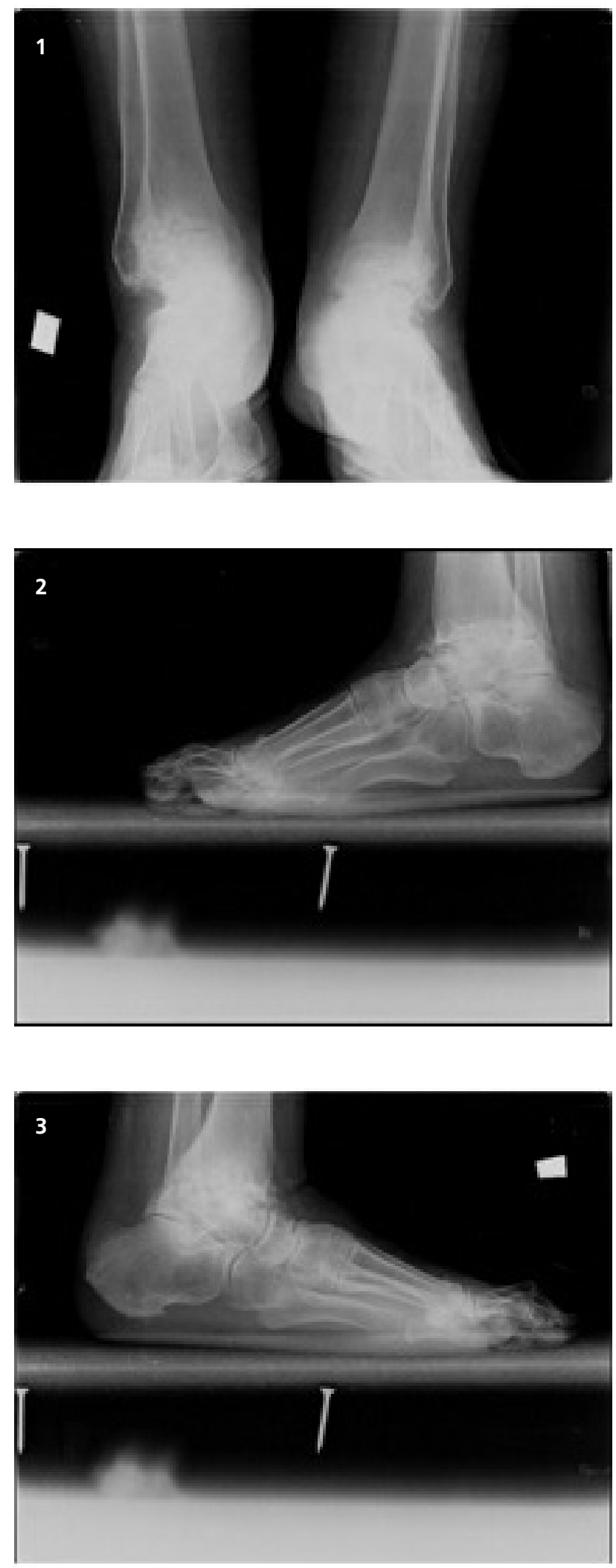

Şekil 1, 2 ve 3. Ayak bileği radyografilerinde, tibiotalar eklem aralığında ileri derecede daralma, talar kubbede belirgin talus ve tibiada destrüksiyon, santral erozyonlar, periartiküler skleroz, kist ve osteofit oluşumları izlenmektedir. 


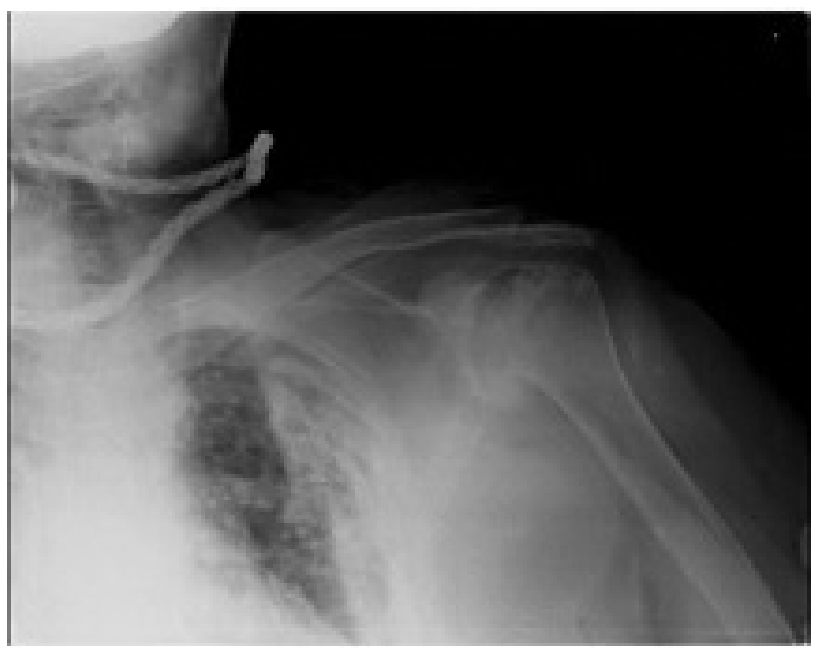

Şekil 4. Sol omuz grafisinde, eklem mesafesinde daralma, glenoid ve humerus başında kortikal destrüksiyon, lateral osteofit oluşumu ve humerus başının superolaterale yer değiştirdiği görülmektedir.

etkinin inflamazom-interlökin-1 yolağından bağımsı olduğunu ve bu sürecin destrüktif osteoartrit patogenezinde rol oynayabileceğini vurgulamışlardır.

Illeri yaş, osteoartrit gelişimi için bir risk faktörü olarak kabul edilmektedir. Invitro çalışmalarda, yaşla birlikte artiküler kartilajda sentetik kondrosit aktivitesinin azaldığı gösterilmiştir. Yaşı osteoartritli hastalarda, sarkopeni, propriosepsiyonun azalması ve fiziksel disabilitenin artışı gibi faktörler nedeniyle, nöromusküler koruyucu mekanizmaların azaldığı bilinmektedir. Primer osteoartritin ileri yaşlarda ortaya çıkması, dokuların yaşlanma sürecinde, ayak bileği osteoartritinin gelişmesi için gereken sürenin relatif olarak uzun olması nedeniyle açıklanabilir (10). Klinik olarak ayak bileği osteoartriti olan hastalar, yük vermekle artan ağrı, yürüme bozuklukları ve disabilite nedeniyle hekime başvurmaktadırlar $(6,11)$. Hastamızda sol omuz ile birlikte her iki ayak bileğinde destrüktif osteoartrit saptanmıştır. Öyküsünde 23 yıl önce tarif edilen, ayaklarına ip dolanarak bir hayvan tarafından sürüklenme şeklindeki travma, bilateral ayak bileğinde traksiyon zorlanmasına yol açmış ve destrüktif osteoartrite zemin hazırlamış olabilir. Aynı travma beraberinde omuz ekleminde de zorlanmaya neden olmuş olabilir. Posttravmatik osteoartrit bulgularının daha erken yaşlarda semptom vermesi beklenirken, hastamızda yaklaşık 20 yıl sonra semptomların ortaya çıkışı daha çok primer osteoartriti akla getirmektedir. Yetmiş iki yaşındaki hastamız, Victor ve ark.'nın (10) çalışmasında, primer ayak bileği osteoartritli hastaların ileri yaş grubunda olmaları ile benzerlik göstermektedir. Omuz ve ayak bileği eklemleri, nadir tutulan eklemler olması dolayısılla dikkat çekicidir. Omuz ve bilateral ayak bileği eroziv osteoartriti saptanan bu olgu ile, yaşı kadınlarda disabilite nedeni olabilen destrüktif osteoartrit vurgulanmıştır.

\section{Kaynaklar}

1. Atay MB. Osteoartrit. In: Beyazova M, Gökçe Kutsal Y, editors. Fiziksel Tıp ve Rehabilitasyon. Ankara: Güneş Tıp Kitabevleri; 2011. p. 2533-62.

2. Campion GV, McCrae F, Alwan W, Watt I, Bradfield J, Dieppe PA. Idiopathic destructive arthritis of the shoulder. Semin Arthritis Rheum 1988; 17:232-45

3. Nelson $A E$, Jordan JM. Osteoarthritis: epidemiology and classification. In: Hochberg MC, Silman AJ, Smolen JS, Weinblatt $\mathrm{ME}$, Weisman $\mathrm{MH}$, editors. Rheumatology. Philadelphia: Mosby Elsevier; 2011. p. 1709-16.

4. Dinçer F. Osteoartritte klinik özellikler. In: Arasıl T, editor. Kelley Romatoloji. Ankara: Güneş Kitabevi; 2006. p. 1514-27.

5. Fardet L, Messow M, Maillefert JF, Dougados M. Primary glenohumeral degenerative joint disease: factors predisposing to arthroplasty. Clin Exp Rheumatol 2003;21:13-8.

6. Altman RD. Clinical features of osteoarthritis. In: Hochberg MC, Silman AJ, Smolen JS, Weinblatt ME, Weisman MH, editors. Rheumatology. Philadelphia: Mosby Elsevier; 2011. p. 1723-30.

7. Barg $A$, Pagenstert $G l$, Hügle $T$, Gloyer $M$, Wiewiorski $M$, Henninger $\mathrm{HB}$, et al. Ankle osteoarthritis: etiology, diagnostics, and classification. Foot Ankle Clin 2013;18:411-26.

8. Schaefer KL, Sangeorzan BJ, Fassbind MJ, Ledoux WR. The comparative morphology of idiopathic ankle osteoarthritis. J Bone Joint Surg Am 2012;94:181.

9. Lübbeke A, Salvo D, Stern R, Hoffmeyer P, Holzer N, Assal M. Risk factors for post-traumatic osteoarthritis of the ankle: an eighteen year follow-up study. Int Orthop 2012;36:1403-10.

10. Valderrabano V, Horisberger M, Russell I, Dougall H, Hintermann B. Etiology of ankle osteoarthritis. Clin Orthop Relat Res 2009;467:1800-6

11. Ritterman SA, Fellars TA, Digiovanni CW. Current thoughts on ankle arthritis. R I Med J 2013;96:30-3.

12. Ea HK, Chobaz V, Nguyen C, Nasi S, van Lent P, Daudon M, et al. Pathogenic role of basic calcium phosphate crystals in destructive arthropathies. PLoS One 2013;8:57352. 